\title{
Norois
}

Environnement, aménagement, société

$236 \mid 2015$

Présence chinoise en Arctique, nautisme, ville-port, vulnérabilité, inondation

\section{Vieillir chez soi. Les nouvelles formes de maintien à domicile}

Sébastien Fleuret

\section{OpenEdition}

\section{Journals}

Édition électronique

URL : https://journals.openedition.org/norois/5737

DOI : $10.4000 /$ norois. 5737

ISBN : 978-2-7535-4945-6

ISSN : $1760-8546$

\section{Éditeur}

Presses universitaires de Rennes

\section{Édition imprimée}

Date de publication : 30 décembre 2015

Pagination : 93-94

ISBN : 978-2-7535-4903-6

ISSN : 0029-182X

\section{Référence électronique}

Sébastien Fleuret, «Vieillir chez soi. Les nouvelles formes de maintien à domicile », Norois [En ligne], 236 | 2015, mis en ligne le 01 juin 2016, consulté le 01 février 2022. URL : http://

journals.openedition.org/norois/5737 ; DOI : https://doi.org/10.4000/norois.5737

Ce document a été généré automatiquement le 1 février 2022

(c) Tous droits réservés 


\title{
Vieillir chez soi. Les nouvelles formes de maintien à domicile
}

\author{
Sébastien Fleuret
}

\section{RÉFÉRENCE}

Laurent Nowik, Alain Thalineau (dir.), 2014. Vieillir chez soi. Les nouvelles formes de maintien à domicile, Rennes, PUR, coll. « Le Sens social », 236 p.

Le livre s'ouvre sur un court récit singulier, celui de Madeleine qui s'installe en foyer logement. Cela permet de poser le sujet: la mobilité résidentielle vers un habitat intermédiaire pour les personnes âgées qui engendre de nouveaux modes d'habiter, un nouveau chez-soi où vieillir et qui n'est pas nécessairement le logement où l'on a vécu la majeure partie de sa vie. La mobilité résidentielle pour s'adapter aux difficultés liées au vieillissement est présentée par A. Thalineau comme une stratégie d'adaptation, une façon, tout en déménageant, de garder un logement à soi. Cet habitat intermédiaire dont il est question diffère des établissements d'hébergement pour personnes âgées dépendantes (EHPAD). Il résulte autant, voire plus, d'une construction sociale et d'initiatives du secteur privé que d'une politique publique de maintien à domicile. Ce livre s'articule en deux parties. La première traite spécifiquement des formes d'habitat intermédiaire en France et la seconde expose les limites des politiques du maintien à domicile. Vingt-deux auteur(e)s ont contribué à l'ouvrage : médecins, ergothérapeutes, sociologues, gérontologues, architectes, socio-démographes... mais aucun géographe n'y a participé, ce qui est troublant sur un tel sujet. Ce livre semble issu d'un travail éditorial principalement effectué à la suite du colloque «Vieillir chez soi - vivre entre soi ? Les habitats intermédiaires en question » qui s'est tenu à Tours en 2013 et dont, curieusement, il n'est pas fait mention dans l'ouvrage. Les quatre premiers chapitres de la partie 1 définissent et décrivent les formes de l'habitat intermédiaire en pointant leur vocation sociale alors même que le recentrage de l'État sur la dépendance a laissé 
ce champ du logement pour personnes âgées non dépendantes au secteur associatif et au privé à but lucratif.

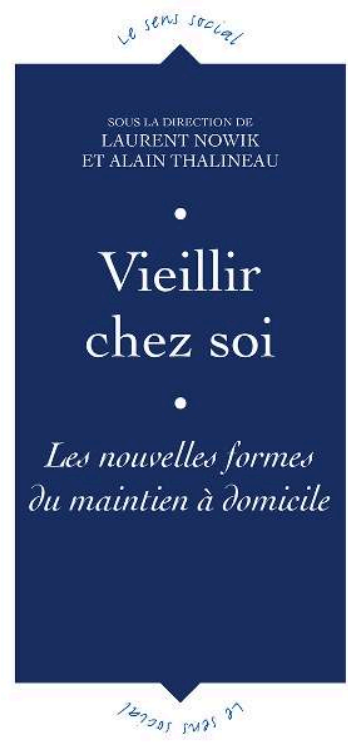

Les deux autres chapitres de cette première partie portent plus sur les parcours et trajectoires résidentielles autour de cet habitat qui est un entre-deux et peut être perçu comme l'antichambre de la maison de retraite pour personne dépendante. Autour de la notion de parcours résidentiel se joue la question du continuum de l'habiter, combiné avec les enjeux de l'accompagnement social et du soin. Ces aspects conduisent, dans le dernier chapitre portant sur l'exemple de l'île de la Réunion, à poser la question des politiques publiques qui constituent le sujet principal de la deuxième partie du livre. Cette deuxième partie est composée de 5 chapitres et pose les limites des politiques de maintien à domicile, étudiées sous différents angles. Le premier est économique et consiste à observer le marché de la perte d'autonomie. Le deuxième point de vue est aménagiste et se formule de différentes façons : aménager le domicile face à la perte d'autonomie pose des enjeux de préservation d'une certaine familiarité de l'espace habité, déménager pose l'enjeu du maintien d'un cadre relationnel, imaginer un logement de type intermédiaire suppose également de penser le cadre de vie dans lequel il s'insère en proposant, par exemple, des services adaptés. L'angle de vue suivant consiste à replacer la personne âgée dans sa sphère familiale. L'auteur analyse ici les variations de situations des personnes âgées au regard de l'habitat, selon les configurations familiales et notamment la proximité ou l'éloignement des enfants. Enfin le dernier chapitre évoque le risque d'isolement et ses déterminants (âge, sexe, état de santé, capital économique, niveau d'éducation...). En conclusion, cet ouvrage brosse un portrait assez complet et juste de l'habitat intermédiaire. Il pose également bien les enjeux qui y sont liés à plusieurs échelles. Pour l'individu il s'agit de continuer à vivre chez-soi, autant que possible sans rompre le continuum du parcours de vie qui a précédé. À l'échelle de l'entourage, il s'agit de maintenir des liens relationnels, lesquels sont également un facteur déterminant de la capacité de la personne à vivre à domicile, 
au même titre que son niveau de vie économique (sa pension de retraite) qui conditionnent la capacité des personnes à passer cet "entre-deux». Ainsi l'ouvrage expose un certain nombre d'inégalités (de revenus, de sexe notamment) qui nécessitent d'être compensées, ce qui incombe aux politiques publiques et aux bailleurs essentiellement.

\section{AUTEURS}

\section{SÉBASTIEN FLEURET}

Université d'Angers 